\title{
Procedures of Fatigue Analysis by Supporting Direct Load Application on Midship Sections
}

\section{Ozgur Ozguc}

Fatigue evaluation of ship structures using direct procedures are supported by a developed tool to be used in calculation methods to calculate fatigue loads are standard the analysis procedures. Three details of local fine mesh models practice today. There are several numerical codes available such as deck erection butt weld, longitudinal stiffener through for use in analyses of these fatigue loads. In addition to the web-frame, and bottom erection butt weld have been analysed. varying degrees of computational complexity associated with The results have been compared with the component-based fatigue prediction methods, the inherent uncertainties of these approach. For some of the details there are comparable results, procedures are also large. This paper introduces the procedure but for others the results vary significantly. The typical trend is for stochastic fatigue analysis of typical midship models with that the details heavily influenced by the external pressure (side direct load transfer applied, where an oil tanker is considered. longitudinal) give less comparable results than e.g. a detail in the It also covers a comparison of the results with the component- main deck mainly influenced by global loads. A comparison of based approach included in the DNVGL Class Note 30.7: "Fatigue the effect of reducing versus not reducing the pressure amplitude Assessment of Ship Structures". The "real" case analysis includes in the waterline on the fatigue life has also been performed and both internal pressure loads from tank fluids as well as external discussed.

pressure adjusted for wet and dry surfaces in the waterline area, according to DNVGL Class Note 30.7. Local fine mesh models of fatigue details have been analysed using the sub-modelling technique. The procedure performs well on a typical midship model apart from the file sizes of the generated load transfer files. With 25 wave periods and 12 different headings, the analysed 3 -cargo-hold model $(1 / 2+1+1 / 2)$ in the midship area had to be split into four super elements in order to get the analysis through finite element analyses. The procedure is suitable for vessels where warping (torsion) is of less importance. The described

\section{KEY WORDS}

$\sim$ Fatigue assessment

$\sim$ Stochastic method

$\sim$ Component-based approach

$\sim$ Finite element analysis

$\sim$ Midship section

Istanbul Technical University, Dept. of Naval Architecture and Ocean Engineering

e-mail: ozguco@itu.edu.tr

doi: 10.7225/toms.v09.n01.001

This work is licensed under (cc) BY

\section{INTRODUCTION}

Precise assessment of the fatigue of ship structures is an important part of structural integrity. In critical locations of oceangoing ships, fatigue cracks can occur earlier than expected, as a result of accumulated fatigue damage. In certain practical cases, the data set required for accurate estimation of fatigue damage can be obtained either through numerical simulation or direct measurement, but in practice the size of the above data set is often limited and not large enough for accurate calculation of the direct fatigue damage.

Mao et al. (2014) conducted a comparative analysis that used different traditional direct fatigue calculation methods for two container vessels. The amount of fatigue damage calculated using these methods has been compared with that obtained from full-scale measurements. Most of the direct calculation approaches examined have yielded similar fatigue damage predictions. The procedure using non-linear hydrodynamic analysis of the time-domain and the finite-element approach provided and recommended fair and conservative results of fatigue damage. 
Parihar et al. (2017) adopted an approach to assessing stress transfer function based on the direct application of moments such as vertical bending, horizontal bending, and torsional moments calculated by a frequency-domain-based seakeeping code. Multipoint Constraint (MPC) approach was used for bending moment application. Comparison was made of the structural responses measured using direct application of the bending moments (Method 1) and the panel pressures (Method 2). The role of stress transfer assessed was employed for analysing spectral fatigue. In addition, the study produced a technique for determining spectral fatigue using direct application of moments of bending.

Xiang-chun et al. (2006) used a spectral method that was considered the most reliable although the procedure was complicated and time-consuming. Critical technical items such as wave pressures and inertial forces due to loads, stress extraction and the RAO stress calculation have been addressed. In addition, four key technical details - loading application, displacement boundary condition, calculation of RAO stress, and fatigue stress extraction were addressed in detail. The resolutions were effective and efficient, which could guide the engineers to perform spectral fatigue analysis more precisely and more quickly where the NASTRAN FE solver was employed.

Kozak and Górski (2011) have applied a number of approaches to estimating the fatigue life of the hull, whose structural elements have been provided. In practice, certain procedures based on nominal stress were applied to "hotspot" stress or notch stress, which constituted the basis for the determination of fatigue life using the design curves of $\sigma-\mathrm{N}$. The current proposals were critically computed and their drawbacks are presented in this study.

Wang and Shao (2019) addressed three methods for calculating accumulated fatigue damage to ship structures on the basis of a direct analysis. The methods applied were in accordance with a short-term distribution, a long-term distribution based on a short-term distribution, and a major stress calculation. For each procedure, the corresponding formulations and flow charts were presented. The findings revealed that the accumulated fatigue damage calculated varies and a great deal of attention should be paid to each.

Gaidai et al. (2019) have contributed to the development of novel fatigue prediction methods that have made more efficient use of the limited data available. Continuous stress time series covering almost two years of duration have been computed. Rainflow counting method was subsequently employed for the evaluation of accumulated fatigue damage. Efficient tailextrapolation technique has been proposed to accurately predict fatigue damage. The proposed technique used the available data more efficiently than the estimation of direct fatigue.

Niemi et al. (2018) provided several hints regarding stress determination and interpretation in finite element models and discussed the choice of suitable finite elements with respect to structural hot-spot stress analyses, and covered shell as well as solid elements. Three methods of deriving structural hot-spot stresses were explained and discussed in detail such as the through-thickness stress linearisation at the hot-spot, the surface stress extrapolation to the hot-spot, and the determination of the structural hot-spot stress at a certain point in front of or below the hot-spot. Finally, detailed hints were given regarding the choice of the element type and size as well as stress evaluation in case of coarse and fine finite element meshes, supplemented by some remarks on the weld modelling when using shell elements in the fatigue assessment.

Magoga (2019) provided validation of spectral fatigue analysis (SFA) against test results, followed by a review on the sensitivity of fatigue damage to various parameters sustained in a naval HSLC. Furthermore, fatigue analysis was affected by uncertainty in input parameters and modelling. It was discovered that fatigue damage was most sensitive to significant wave height, although the relative importance of the speed and direction increased when operating conditions were taken into account. The work was related to the long-term management of naval ship structures.

Currently in the rules for fatigue evaluation of structures exposed to intense alternating service loading the Stress-Life (S-N) criteria, versions of the nominal stress approach, hot-spot stress approach and notch-stress approach were suggested based on the use of the stress range as a representation of the present damage.

Petinov and Guchinsky (2018) examined the criteria and procedures for assessing the fatigue properties of structures, accompanied by a series of approximations and uncertainties. According to these researchers, the strain-life and inelastic strain energy requirements for fatigue failure and approaches may provide a physically and mechanically more accurate procedures, specific with intrinsic sources of approximations. The essence of approximations in the methods was briefly commented and the fatigue evaluation techniques and implementations were provided with feasible means of improvement.

Bardetsky and Lee (2016) applied a new comprehensive analytical procedure for predicting crack propagation under seawave loading by spectral fatigue analysis, beam theory, fracture mechanics and an equivalent stress intensity factor (SIF) range concept. The analytically obtained SIF range was validated by the FE modelling of the damaged vessel undergoing dynamic sea-wave loading. The analytical procedure for predicting crack propagation has been demonstrated for a typical, modern 170,000 DWT bulk carrier in full load condition. The findings of this work could be utilized to guide rational decision-making when assessing the residual strength of a vessel for the transit voyage from the site of the accident to a repair facility. 
Parunov et al. (2013) used finite element (FE) method to calculate stress concentration factors (SCFs) using shell elements, which were then compared with their specified values according to classification societies' guidelines. The FE analysis has been used for various configurations of the details that may appear in practice. A simplified procedure for calculating fatigue life has been used and the differences in calculated fatigue life due to the differences in SCFs have been evaluated. The methodology for calculating SCFs was then verified on the basis of the FE analysis of the details of the derived hot-spot stress target and of the corrected SCFs. The effect of SCF correction on fatigue life was discussed. Specific methods were considered for extrapolating stresses to the weld foot, and the resulting SCFs were compared with the values provided by the classification societies' regulations. The study findings may be used in the process of harmonization of ship structural rules and in analyses of fatigue reliability.

González (2016) examined the key characteristics of the most popular fatigue analysis methodologies, and highlighted the drawbacks and uncertainties involved. Further, developments in reliability-based approaches have been suggested for a more accurate assessment of the fatigue of ship unloaders.

Fricke (2015) addressed various approaches, which highlighted their advantages and limitations. In this relation, the troublesome distinction between crack initiation and propagation phases was addressed, followed by considerations of other parameters that have a major impact on the fatigue actions of welded joints but are regarded differently in approaches, such as plate thickness and stress gradient effects, multiaxial stress conditions, welding-induced distortions and residual stress. In conclusion, ways to improve the fatigue behaviour of the welded structures have been addressed, either during design by reducing stress concentration or during manufacturing by improved quality, post-welding treatment or by special material characteristics.

Kim et al. (2009) performed a fatigue strength evaluation for a container vessel's side shell longitudinal connections, using both the hot-spot stress and structural stress methods. A consistent procedure of computing extrapolated hot-spot stress for design purposes based on converging hot-spot stress was described and current fatigue guidance was evaluated. Fatigue capacity predicted by both methods, i.e. hot-spot stress and structural stress approaches, at hot-spot locations of the typical ship structure was compared and discussed.

Fatigue damage reduces the structure's load-bearing capacity and can lead to leakage, leading to pollution, cargo mixing or gas accumulating in enclosed spaces, in severe cases; such structural damage could potentially lead to catastrophic failure or total vessel loss (Ozguc, 2017). Ship longitudinals are significant structural components in the ship's side shell construction. The wave loads cause major dynamic stresses below the mean water level in the side shell. This has resulted in a number of fatigue cracks in the welded connections between side longitudinal stiffeners and transverse frames and ship bulkheads (Ozguc, 2018).

This paper introduces the procedure for stochastic fatigue analysis of typical midship models with direct load transfer applied, in which an oil tanker is considered. It also covers a comparison of the results with the component-based approach included in the DNVGL Class Note 30.7. The "real" case analysis includes both internal pressure loads from tank fluids as well as external pressure adjusted for wet and dry surfaces in the waterline area according to Det Norske Veritas, DNVGL Class Note 30.7: "Fatigue Assessment of Ship Structures". Local fine mesh models of fatigue details have been analysed using the submodelling technique. The procedure performs well on a typical midship model apart from the file sizes of the generated load transfer files. With 25 wave periods and 12 different headings, the analysed 3-cargo-hold model $(1 / 2+1+1 / 2)$ in the midship area had to be split into four super elements in order to get the analysis through SESTRA software. The procedure is suitable for vessels where warping (torsion) is of less importance. The described procedures are supported by Excel spreadsheets to be used in the analyses' procedures. Three details (local fine mesh models) have been analysed. The results have been compared with the component-based approach described in DNVGL Class Note 30.7. For some of the details there are comparable results, but for others the results vary significantly. The typical trend is that the details heavily influenced by the external pressure (side longitudinal) give less comparable results than e.g. a detail in the main deck mainly influenced by global loads. A comparison of the effect of reducing versus not reducing the pressure amplitude in the waterline on the fatigue life has also been performed and discussed.

\section{SELECTION OF FATIGUE ANALYSIS METHODS}

The analysis procedure is adopted on an oil tanker, and its principle dimensions are listed in Table 1 below.

Table 1.

Main particulars of the oil tanker analysed.

\begin{tabular}{ll} 
Length over all & $340 \mathrm{~m}$ \\
\hline Length between perpendiculars & $325 \mathrm{~m}$ \\
\hline Breadth & $56 \mathrm{~m}$ \\
\hline Depth & $28.8 \mathrm{~m}$ \\
\hline Draft & $22.3 \mathrm{~m}$ \\
\hline Deadweight & 307,400 tons \\
\hline
\end{tabular}


The most sophisticated method is full stochastic (spectral) analysis. The full stochastic (spectral) analysis employs both global and local finite element models to determine the stress response and may be used for any kind of structure. As basis for the stochastic fatigue analysis, a linear frequency domain wave load analysis is carried out to determine load transfer functions for external pressures and vessel motions. Global integrated responses such as vertical and horizontal bending moments and shear forces are also calculated. From the load transfer functions, the stress transfer functions are determined by either a component stochastic or a full stochastic approach.

In the component stochastic method the stress transfer functions are established by the load transfer function multiplied with a unit load stress factor for each load component. The load components typically include global wave bending moments, external and internal pressures. The combined stress response is found by a complex summation of the stress transfer functions for each individual load component.

This paper introduces the procedure for component stochastic fatigue analysis of midship models with direct load transfer applied on a typical DNVGL NAUTICUS HULL midship model, where the model used is an oil tanker vessel. The model consists of 44,556 nodes and 76,623 elements with four elements between transverse frames.

The procedure offers a substantial reduction in time when considering a full stochastic calculation of fatigue life in the midship area. The procedure performs well on a typical midship model apart from the file sizes of the generated load transfer files. With 25 wave periods and 12 different headings, the analysed midship 3D cargo hold model $(1 / 2+1+1 / 2)$ had to be split into four super elements in order to get the analysis through SESTRA.

The "real" case analysis includes both internal pressure loads from tank fluids as well as external pressure adjusted for wet and dry surfaces in the waterline area according to DNVGL Class Note 30.7. Local fine mesh models of fatigue details have been analysed using the sub-modelling technique. The described procedures are supported by developed tool to be used in the analysis procedures.

The analysis showed that the procedure will be resource demanding using the current DNVGL NAUTICUS standard for mesh on the midship model. After several alterations, the model was divided into 4 super elements and the number of periods analysed was reduced to 25 , resulting in a reduction of 96 load cases.

It is proposed that the same person performs the hydrodynamic analysis and the fatigue analysis in order to ensure that the necessary calculations are performed without too many iterations. Using internal pressure, pressure reduction in the waterline and a local finite element model of the detail investigated, WADAM has to be run 6 times, where WADAM is based on a $3 \mathrm{D}$ sink-source (diffraction-radiation) method coupled to the Morison equation. It has a useful capability of allowing viscous forces to be incorporated in the modelling, which is important for the roll motion of a vessel. Using the same person for both analyses will also reduce the amount of time used to move files back and forth, which can also be time consuming with files of the mentioned size.

Three details of local fine mesh models such as deck erection butt weld, longitudinal stiffener through web-frame, and bottom erection butt weld have been analysed. The results have been compared with the component based approach described in DNVGL Class Note 30.7. A comparison of the effect of reducing versus not reducing the pressure amplitude in the waterline on the fatigue life has also been performed and documented.

The procedure for full stochastic fatigue analysis on a midship model has been tested with simplified fatigue procedure, which is implemented on the Nauticus hull model. The analysis was performed without internal tank pressure, and no local finite element model of fatigue critical details were made.

In order to see how the procedure works in a "real" case in the production line, the "oil tanker" model previously used for component-based fatigue calculations was used. The "oil tanker" is a $1 / 2+1+1 / 2$ tank model with swash bulkheads at its ends modelled according to the current DNVGL NAUTIUCUS HULL standard with one element between stiffeners and four elements between frames, as shown in Figure 1.

The oil tanker studied in this paper has 11 segregated tanks within the modelled midship area. In addition, the large centre tank is divided in two with a swash bulkhead, which is not heavily perforated. This means that the centre tank has to be treated as two separate tanks, i.e. the midship model essentially consists of 12 tanks.

The 12 headings and 25 wave periods have been employed in the analysis. The wave environment is the World Wide scatter diagram and the Pierson-Moskowitz (PM) spectrum has been used. The hydrodynamic panel model is in millimetres and, therefore, the World Wide scatter diagram has to be modified so that the wave heights are in millimetres in order to get consistency in the analysis procedure.

In addition to the midship model, three local fine mesh models have been used as the basis for fatigue calculations, one detail in the deck (butt-weld), one detail in the ship side (side longitudinal) and one detail in the bottom (butt-weld).

The comparison between three types of analysis have been performed. The full stochastic procedure with correction of the pressure in the waterline has been compared with the same procedure without waterline pressure correction and with component-based approach. The comparison has been performed for all three local fine mesh details.

The loads applied to the models consist of section loads (representing loads from the parts of the vessel not modelled), local pressure from waves and fluid in the tanks and inertia forces 


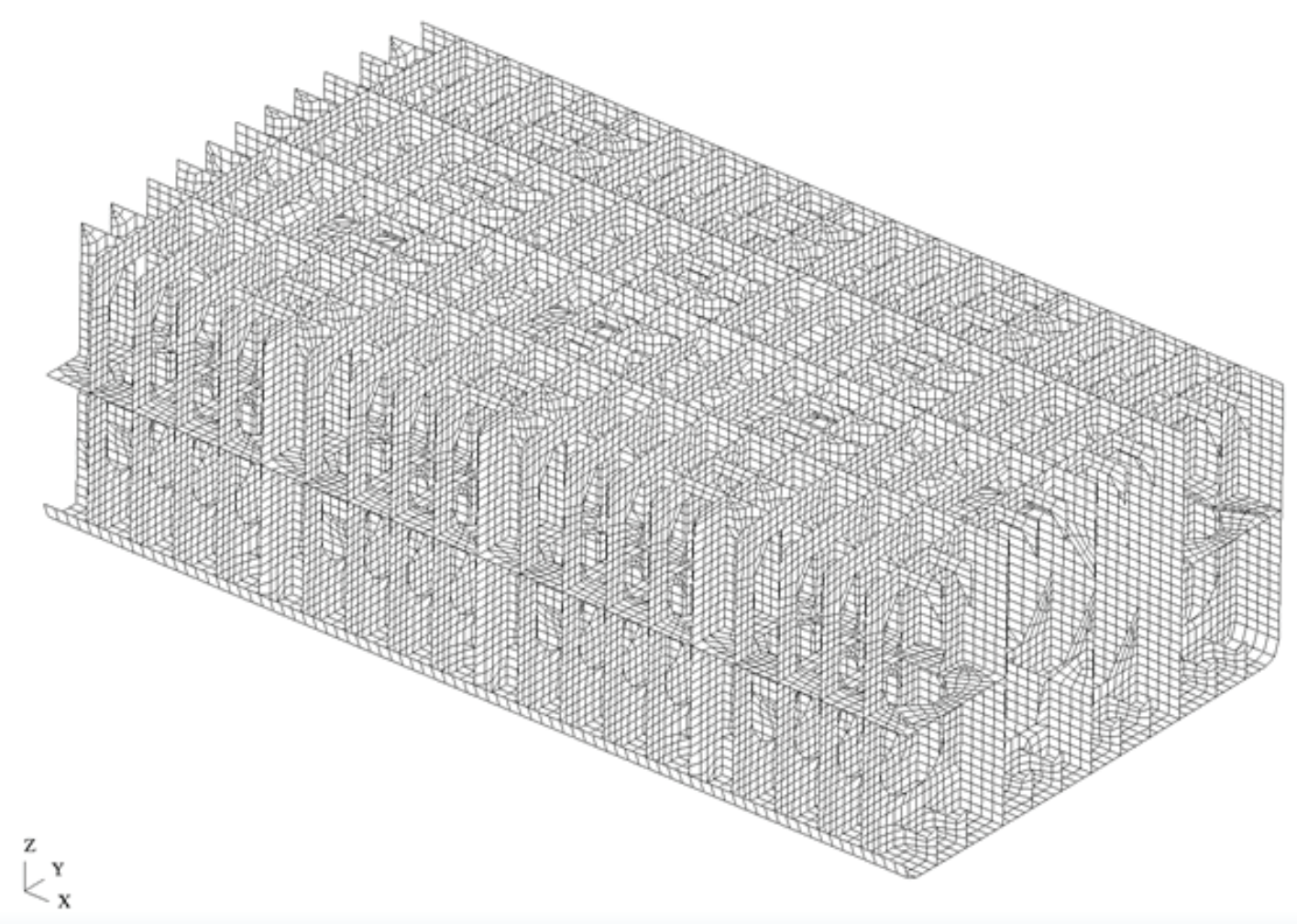

Figure 1.

Finite element midship model of oil tanker - deck and side removed.

from accelerations. On the local models, displacements from the midship model are transferred to the boundaries to represent the global deflections, and external as well as internal pressures from WADAM are transferred to represent the local loads.

Stresses from the finite element model are automatically extracted by STOFAT fatigue module in the SESAM tool. The transfer function is presented as the amplitude only when printed. The maximum stress will always be used as STOFAT module does not consider directionality when choosing principal stress, as described in DNVGL Class Note 30.7, which again will result in conservative results when calculating the fatigue life of a given detail.

Only external pressure was used as local loads, and no local fine mesh models were made for fatigue calculation purposes. The second part will look into this and, in addition, there will be a comparison between the results achieved with the full stochastic method and the component-based method.

The following supplementary tools are being developed.

\section{- Pressure Reduction}

Developed to modify the water line pressure to account for the wet and dry areas, according to the DNVGL Class Note 30.7 "Fatigue Assessment of Ship Structures".

- Sectional Force
Developed to include the sectional forces at the end of the structural midship model to account for loads from not-included structure.

\section{- Merge FEM Files}

Developed to merge the load interface files from the external pressure analysis and internal pressure analysis. Necessary because of large files from separate analysis.

\section{HYDRODYNAMIC ANALYSIS}

The hydrodynamic analysis has to be performed in two or three steps depending on whether internal tank pressures are needed or not. The panel model and mass distribution model should be made according to present procedures for the considered load conditions. Usually two load conditions are adequate and should represent the most frequent conditions in which the vessel will operate, but if it is difficult to relate the vessels lifetime to only two, extra load conditions should be considered.

In order to utilize the new feature with extrapolating and adjusting the pressure profile in the waterline region, the structural model has to be run as panel model in hydrodynamic analysis to get the panel numbers and definition. All panels that 
might get pressures from the changed water line wave profile must have hydro-pressure applied in a tool (e.g. PREFEM, etc). From the hydrodynamic analysis (e.g. WADAM, etc), all the panel information must be stored in the spreadsheet for waterline pressure alteration.

After having made the panel model and the mass model, sectional loads and external pressure must be calculated; both can be calculated in the same hydrodynamic analysis. Section forces for several cuts must be calculated within the boundaries of the midship model in order to assure that the load balance should accordingly be verified in the next stage (e.g. CUTRES, etc). Typically, 7-10 cuts are needed for a proper verification of the transferred forces in addition to the two cuts, which must correspond with the midship model ends.

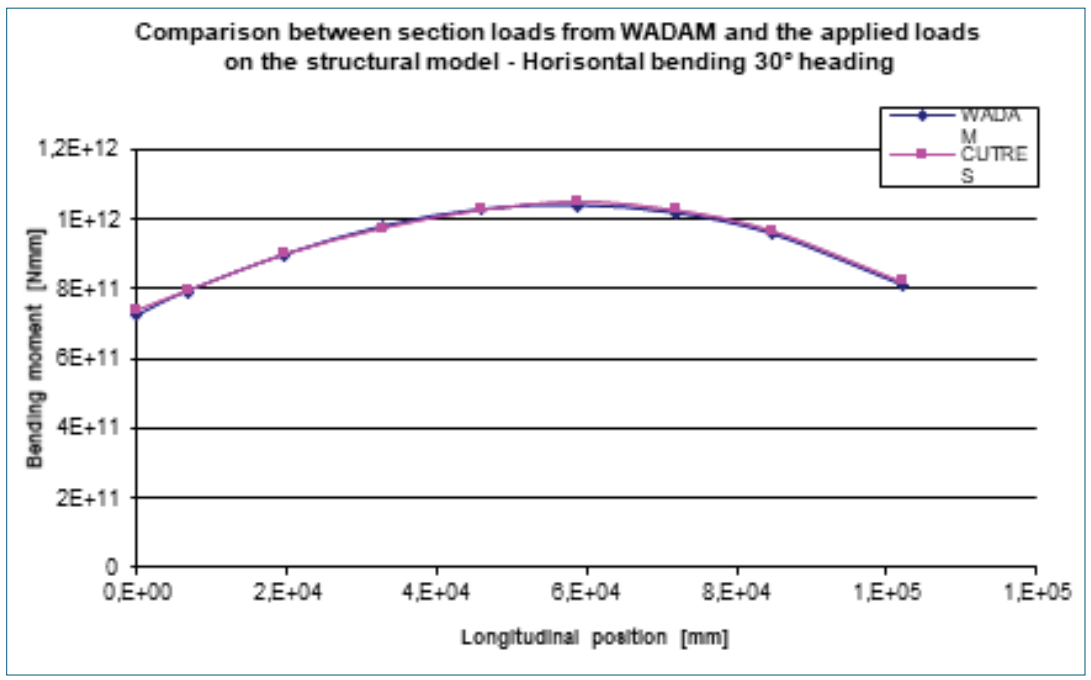

Figure 2.

Comparison between horizontal moment in WADAM and CUTRES.

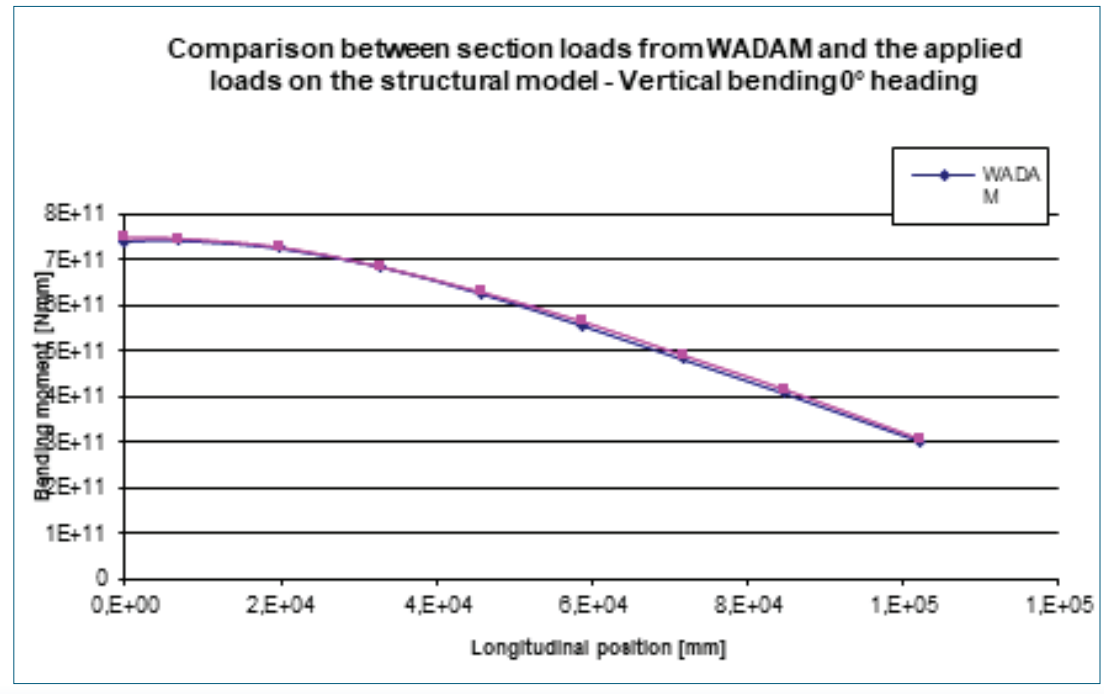

Figure 3.

Comparison between vertical moment in WADAM and CUTRES. 
As seen from Figure 2 and Figure 3, there is a good agreement between the horizontal bending and vertical bending moment from WADAM and CUTRES. Typically, the difference is in the order of $0 \%$ to $1.5 \%$.

If the tank pressure option is necessary, WADAM has to be run a third time. All the tanks must be defined in PREFEM with a separate load case number starting on load case number 2 . All the surfaces which will receive pressures must be defined with hydro dummy pressure cards, with no hydro dummy cards defined on the hull for external loads.

The load interface files from the second and third WADAM analyses must be kept apart as they will get the same names. Prior to the structural analysis, the load interface files from the external and internal pressures must be merged. Together with the structural interface files, they work as the input to the structural analysis.
WADAM allows the option to integrate the section loads (vertical bending moment etc.) from two different directions. It is of great importance that the direction is known for the application of the sectional loads to the finite element model. The sign convention between WADAM and PREFEM is shown in Figure 4.

If local fine mesh models are used for describing the details, WADAM must be run again if the local model is to have internal tank pressure. The local model must be included in the midship model (or another model which describes the tank volume) in order to have a proper description of the tank volume. Otherwise, the internal pressure mapped on the local model will not be correct.

For external pressure, a restart of WADAM according to standard procedure is sufficient to transfer pressure to the hull plates. If the local model is in the waterline region, the pressure profile must be changed on the local model as well.

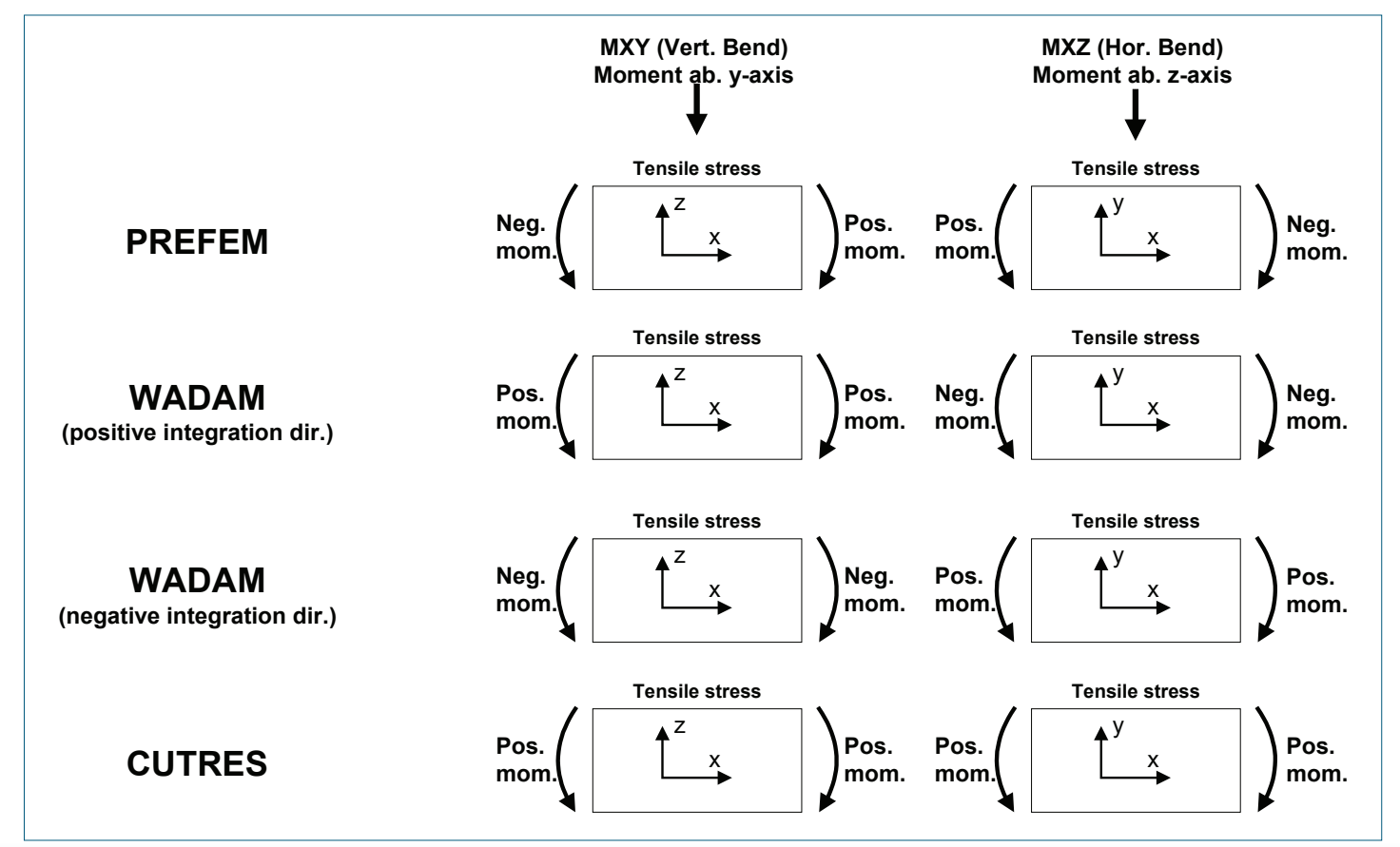

Figure 4

Sign convention in different SESAM software programmes.

\section{STRUCTURAL ANALYSIS}

For the oil tanker, the structural midship finite element model had to be divided into four separate super elements, as seen in Figure 5.

First, the finite element model was divided into two parts, but the same problems occurred even with the split file option.
Then, the number of wave periods was reduced from 33 to 25 , but still the file sizes were too large. Finally, the model was divided into four parts with the split file option, and this allowed the analysis to be completed. The file can be reduced significantly if the results from only a selection of super elements are required and not all, in this case, four. 


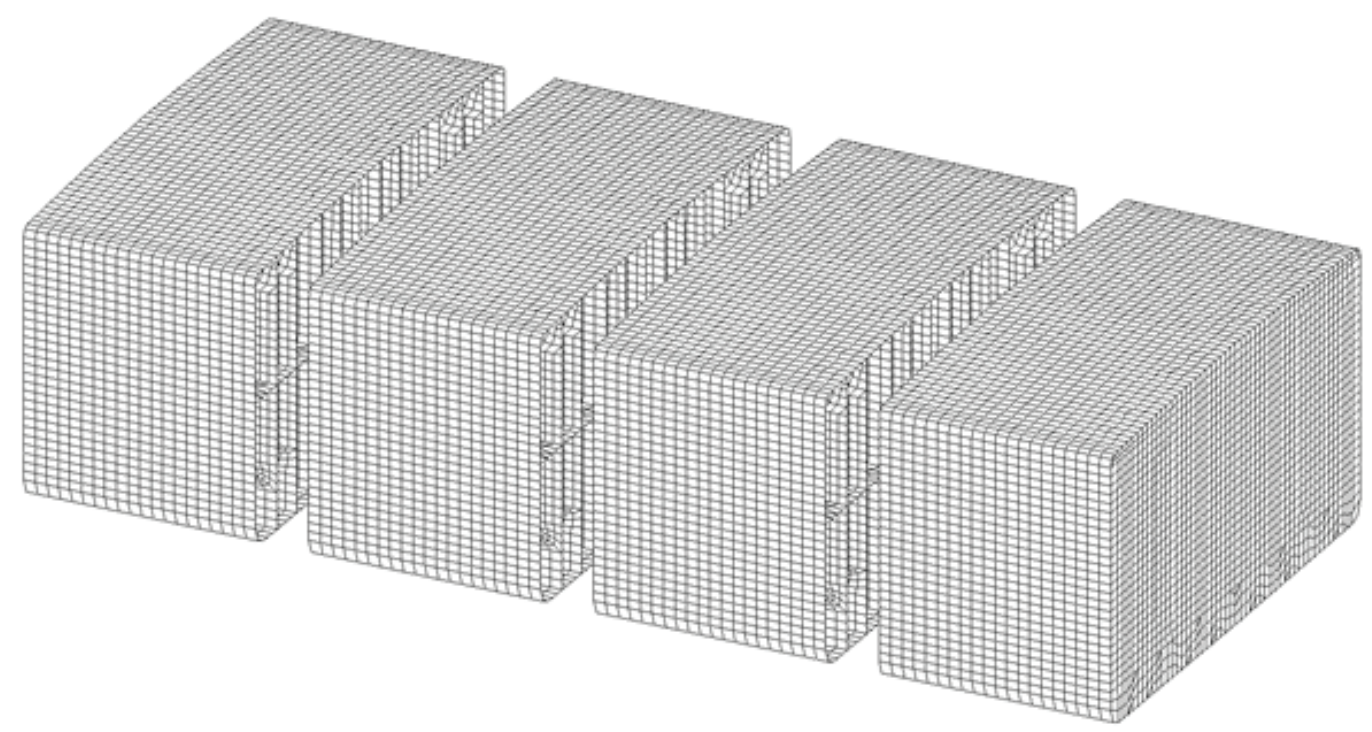

$K^{\mathrm{Z}} \mathrm{X}$

Figure 5.

Separation of "oil tanker" for final analysis.

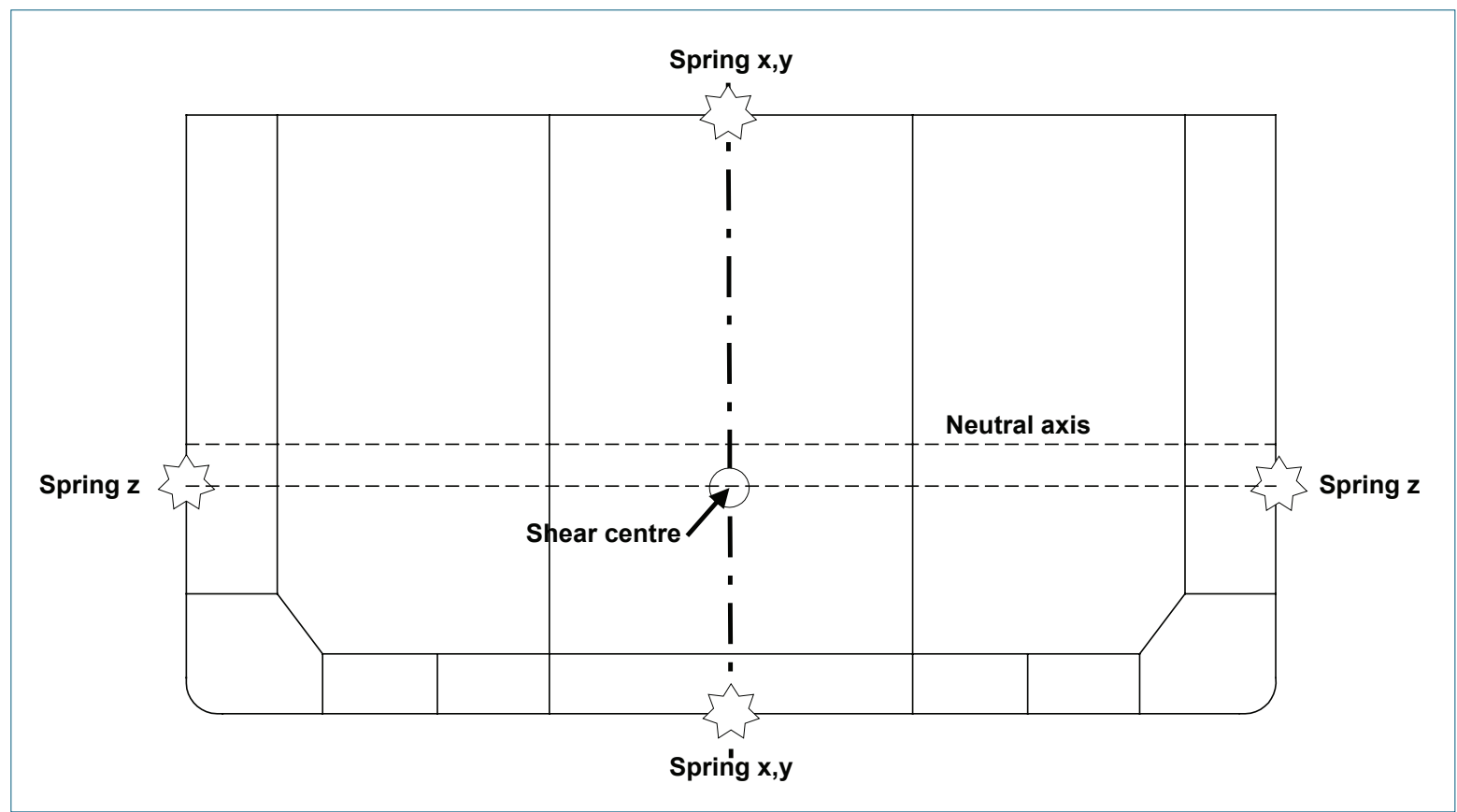

Figure 6.

Midship model spring locations (concentrated springs). 
The midship finite element model was made according to DNVGL NAUTICUS standard, with four elements between the transverse frames and one element between the longitudinal stiffeners. 4-node shell elements were used to describe the plates, and 2-node beam elements were used to describe the longitudinals and secondary stiffening. Longitudinal, vertical, and axial springs were applied to the ends of the model in order to avoid singularities due to the small unbalance which will always be present in structural analysis with direct transfer of loads. Rigid body dependencies were used at the ends to get the sectional loads transferred. Applying rigid body dependencies at the ends results in that the cross section will always move a stiff plane and it is, therefore, not necessary to apply springs which are distributed according to the shear stiffness of the cross section. It is adequate to apply springs in accordance with Figure 6 and Table 2, but the spring stiffness should in any case be small. $1 / 1,000$ of the real stiffness is proposed.

It is noted that if any other boundary conditions than rigid body dependencies for all degrees of freedom are used, other spring definitions may have to be used.

Table 2.

Spring location.

\begin{tabular}{lll} 
Type & Location & Description \\
\hline Springs $x$ & Centreline, deck + (inner) bottom & $\begin{array}{l}\text { Spring constants to be such that an axial force give zero moment about } \\
\text { the neutral axis. }\end{array}$ \\
\hline Springs $y$ & As springs $x$ & $\begin{array}{l}\text { Spring constants to be such that a transverse force give zero moment } \\
\text { about the horizontal axis through the shear centre. }\end{array}$ \\
\hline Springs $z$ & Ship sides & Vertical location of less importance. \\
\hline
\end{tabular}

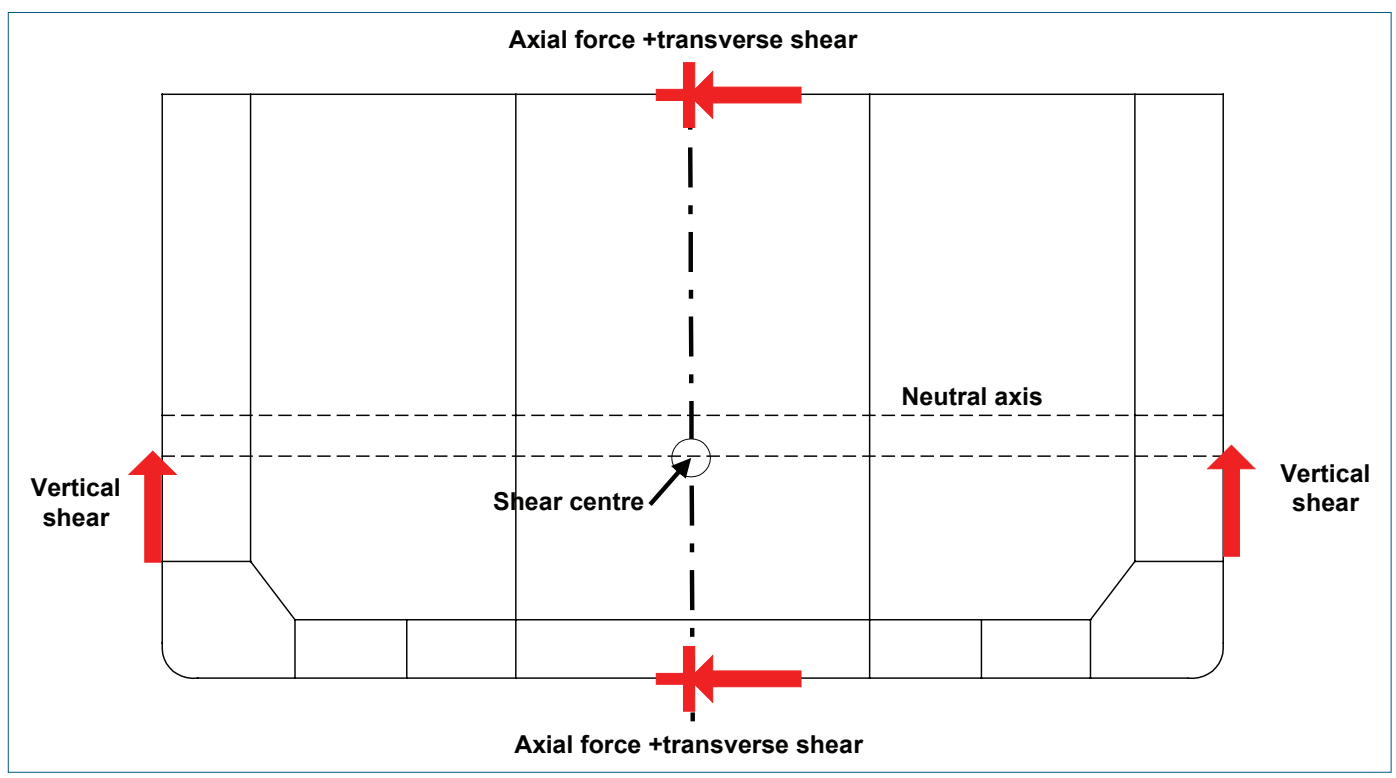

Figure 7.

Midship model load application.

The applied loads are section loads combined with pressure and inertia forces. The section loads are applied at the ends of the finite element model, and are defined as point loads at specific points, as shown in Figure 7 and Table 3.

The section loads are necessary in order to include the effect from the structure and loads not modelled in the midship model.
It is important that the point loads are applied to the model so that they do not introduce any extra unwanted bending moment etc.

External pressure forces are applied to the hull, while inertia forces are accelerations working on the mass of the model, including both tank fluids and steel mass. 
Table 3.

Force location.

\begin{tabular}{lll} 
Type & Location & Description \\
\hline Axial force & Centreline, deck + (inner) bottom & $\begin{array}{l}\text { Force to be such that an axial force give zero moment about the } \\
\text { neutral axis. }\end{array}$ \\
\hline Transverse shear & As axial force & $\begin{array}{l}\text { Force to be such that a transverse force give zero moment about the } \\
\text { horizontal axis through the shear centre. }\end{array}$ \\
\hline Vertical shear & Ship sides & Vertical location of less importance. \\
\hline
\end{tabular}

Prior to the structural analysis, the external pressure from the hydrodynamic analysis is modified according to the procedure described in DNVGL Class Note 30.7. From the hydrodynamic analysis, it is therefore necessary to calculate the long-term pressure (daily level, 10-4) at the waterline based on all the headings included. The amplitude of the intermittent wet and dry area on the hull can then be found and the pressure will be adjusted in this area through a spreadsheet custom-made for this procedure.

Due to the fact that both the internal pressure and external pressure will work on the same panels, but on opposite sides for the hull plates, the load files from the two WADAM analysis (internal and external loads) must be merged. If both external and internal loads are taken from the same WADAM analysis (same $L^{*}$.FEM file), the panels with both external and internal loads will be altered with the procedure for changing the pressure profile in the waterline area. It is noted that these numbers are for the midship model divided into four separate parts.

\section{FATIGUE ANALYSIS}

The stochastic fatigue analysis is performed with DNVGL SESAM software STOFAT module. The input to STOFAT is the result file from the structural analysis, containing all the stress data, together with either interactive input or a batch file input of control parameters such as exposure time, S-N curve, local SCF's, scatter diagram, wave spectrum etc.

Fatigue checks can be performed on both the elements and hot-spots. The element check will report the worst position on the element (highest fatigue damage), while the hot-spot check will report the damage for both the extrapolation points at $t / 2$ and $3 t / 2$ as well as for the hot-spot itself. If the damage at a given node is required, e.g. at $t / 2$, simply specify two or more of the points used for extrapolation at the considered node. The Principal stress is calculated based on the extrapolated component stresses, but only the absolute maximum stress value is used.

\section{COMPARISON OF INTERNAL PRESSURE BETWEEN MIDSHIP MODEL AND LOCAL MODEL}

A comparison between the internal pressure transferred from WADAM to the midship model and the local model has been performed. Since there is a significant difference in the mesh density between the two models, a perfect match cannot be achieved, but it should be comparable with respect to both pressure amplitude and pattern.

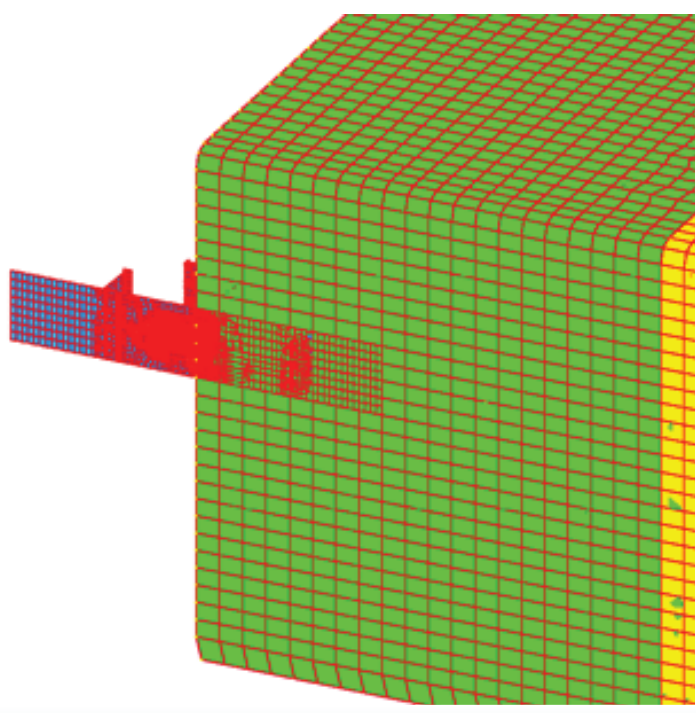

Figure 8.

Local model as part of midship model.

In order to transfer internal pressure to the local models, a part of the midship model will have to be included, as seen in Figure 8. This is in order for WADAM to determine the volume on the tanks for which the internal pressure is to be calculated.

From Figure 9, it can be seen that both the pattern and the pressure amplitudes for both PX (pressure in longitudinal direction) and PY (pressure in transverse direction) matches well between the midship model (left) and the local model (right). The figure represents a part of the transverse bulkhead - side shell connection for longitudinal 11. 
A similar agreement between the midship model and the local model can be seen in Figure 10 for beam seas.

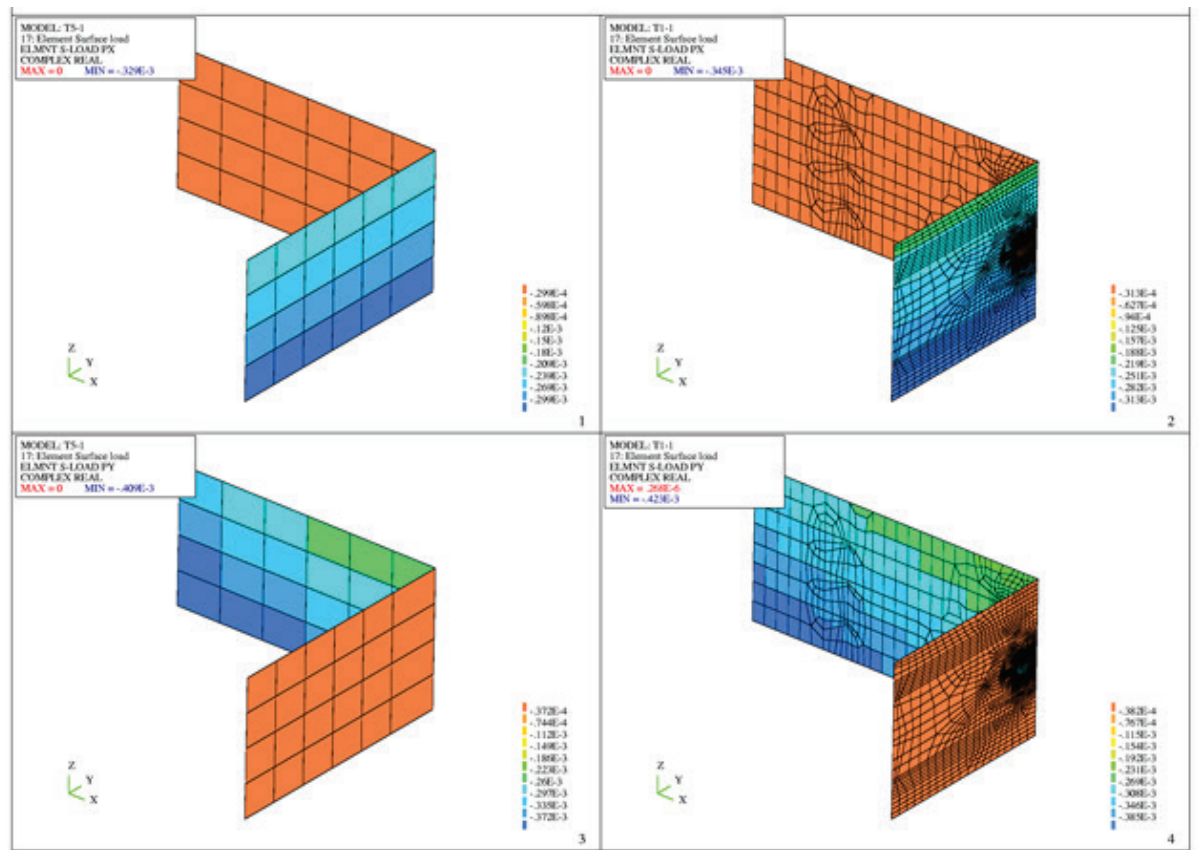

Figure 9.

Pressure comparison for the load case with Heading $0^{\circ}$, and Period $16.5 \mathrm{~s}$.

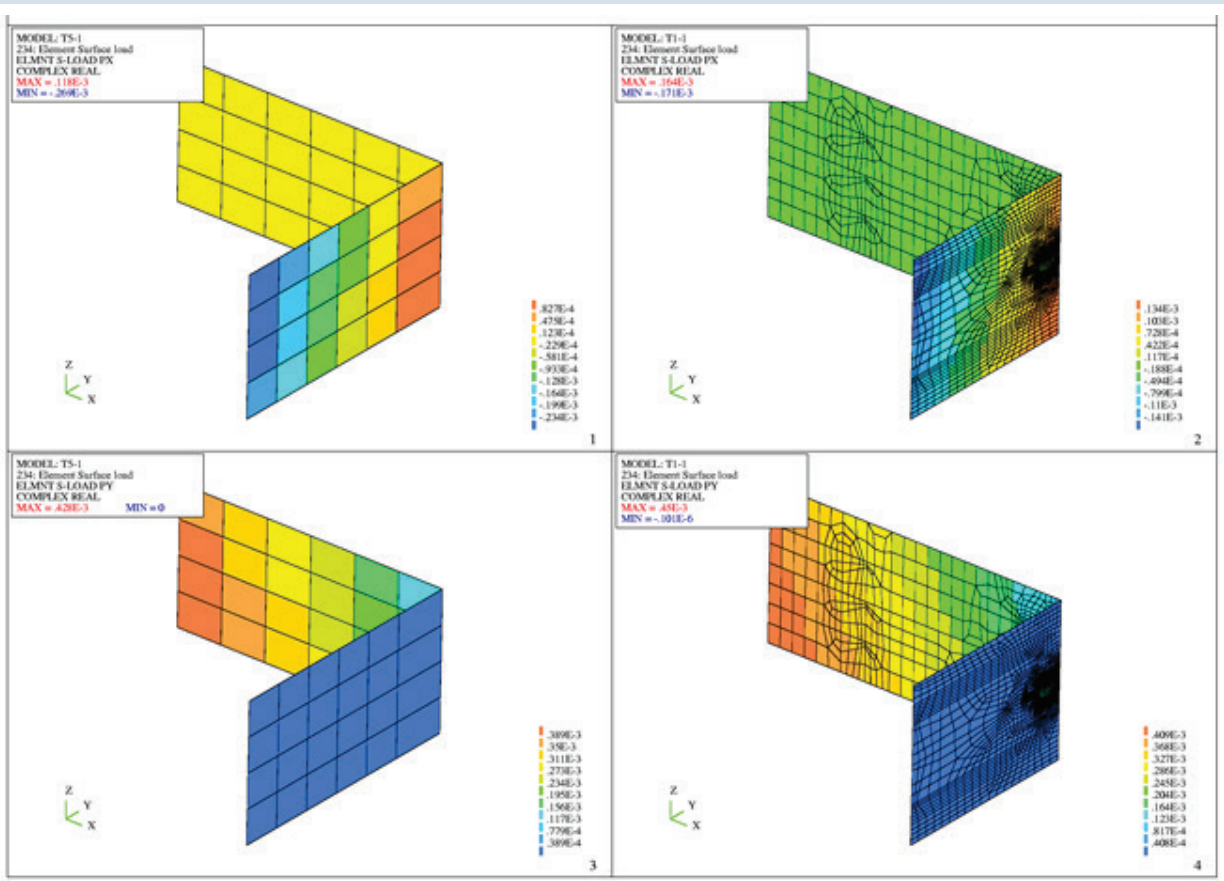

Figure 10.

Pressure comparison for the load case with Heading 2700, and Period 11.5 s. 


\section{COMPARISON OF RESULTS FROM COMPONENT- BASED AND FULL STOCHASTIC FATIGUE ANALYSIS}

Three local models have been analysed with both the component based approach and the direct application approach on the midship model with external pressure reduction in the waterline region. For comparison reasons, the direct application approach on the midship model has also been used without the pressure reduction in the waterline region.

\section{DECK ERECTION BUTT WELD}

The first detail is a deck erection butt with a mouse-hole, as shown in Figure 11, the second is a typical stiffener through web-frame connection, as illustrated in Figure 13, and the third is a bottom erection butt with a mouse-hole, in Figure 15. Only the fully loaded condition has been analysed, and the wave environment is taken as the World Wide scatter diagram from DNVGL Class Note 30.7. It is further assumed that the vessel will operate for 20 years in the same condition.

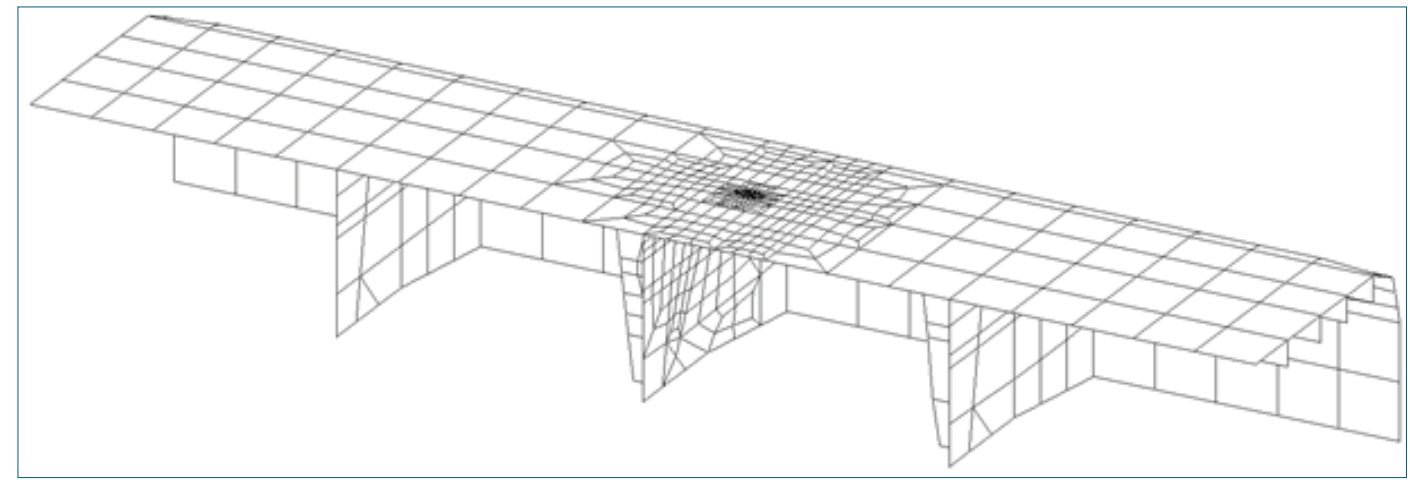

Figure 11.

Local model of deck erection butt weld.

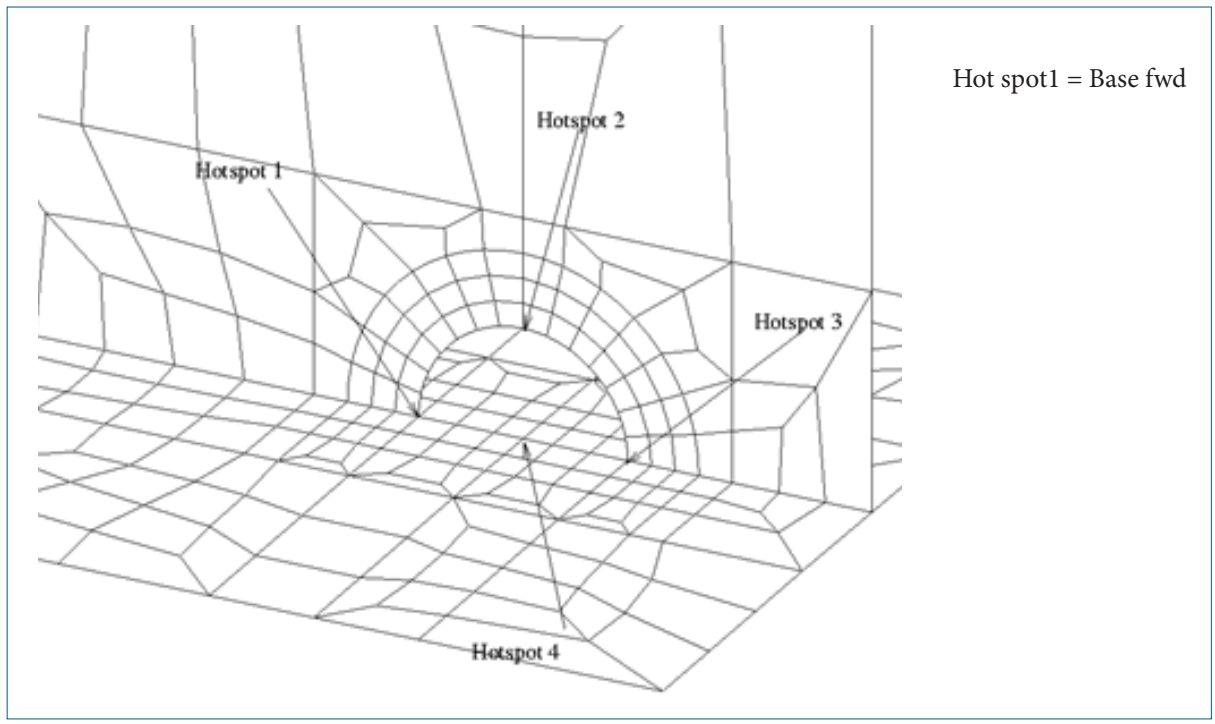

Figure 12.

Hot-spots analysed for deck erection butt weld.

The results for the deck erection butt show a generally good agreement between the two methods. The calculated fatigue life is within $3 \%$ difference between the two methods for the four hot-spots investigated. The effect of not reducing the pressure in the waterline area has little effect for details in the deck area.
The good agreement between the two methods is most likely because the influence of local loads such as pressure forces are almost negligible, hence only global loads will contribute to the stress transfer functions. 
Table 4.

Comparison between component-based and direct application - deck erection butt weld.

Deck erection butt weld

\begin{tabular}{|c|c|c|c|c|c|c|}
\hline & \multicolumn{2}{|c|}{ Component-based } & \multicolumn{2}{|c|}{ Direct with pressure adjustment } & \multicolumn{2}{|c|}{$\begin{array}{l}\text { Direct without pressure } \\
\text { adjustment }\end{array}$} \\
\hline & Damage & Life (years) & Damage & Life (years) & Damage & Life (years) \\
\hline Base fwd & $1.88(a)$ & 10.62 & 1.85 (b) & 10.83 & $1.83(\mathrm{c})$ & 10.94 \\
\hline Mid & $2.33(a)$ & 8.57 & 2.31 (b) & 8.66 & $2.28(c)$ & 8.76 \\
\hline Base aft & $2.16(a)$ & 9.26 & 2.12 (b) & 9.45 & 2.09 (c) & 9.55 \\
\hline \multirow[t]{3}{*}{ Top } & $14.46(a)$ & 1.38 & $14.11(b)$ & 1.42 & $13.98(c)$ & 1.43 \\
\hline & \multicolumn{2}{|c|}{ Component-based } & \multicolumn{2}{|c|}{ Direct with pressure adjustment } & \multicolumn{2}{|c|}{$\begin{array}{l}\text { Direct without pressure } \\
\text { adjustment }\end{array}$} \\
\hline & With & Without & Component & Without & Component & With \\
\hline Base fwd & $1.02(\mathrm{a} / \mathrm{b})$ & $1.03(\mathrm{a} / \mathrm{c})$ & $0.98(b / a)$ & $1.01(b / c)$ & $0.97(c / a)$ & $0.99(\mathrm{c} / \mathrm{b})$ \\
\hline Mid & $1.01(\mathrm{a} / \mathrm{b})$ & $1.02(\mathrm{a} / \mathrm{c})$ & 0.99 (b/a) & $1.01(\mathrm{~b} / \mathrm{c})$ & 0.98 (c/a) & $0.99(\mathrm{c} / \mathrm{b})$ \\
\hline Base aft & $1.02(\mathrm{a} / \mathrm{b})$ & $1.03(\mathrm{a} / \mathrm{c})$ & 0.98 (b/a) & $1.01(\mathrm{~b} / \mathrm{c})$ & $0.97(\mathrm{c} / \mathrm{a})$ & $0.99(\mathrm{c} / \mathrm{b})$ \\
\hline Top & $1.03(\mathrm{a} / \mathrm{b})$ & $1.03(\mathrm{a} / \mathrm{c})$ & 0.98 (b/a) & $1.01(\mathrm{~b} / \mathrm{c})$ & 0.97 (c/a) & $0.99(\mathrm{c} / \mathrm{b})$ \\
\hline
\end{tabular}

\section{SECTION LONGITUDINAL 19}

For the longitudinal stiffener through the web-frame connection, the results are quite different. The variation of fatigue life is large for some of the investigated hot-spots, while it is quite small for others. At this stage, the reason is unclear as the longitudinal is situated below the area where the pressure in the water line is altered.

Table 5.

Comparison between components based and direct application - side long.

Side longitudinal 19

\begin{tabular}{|c|c|c|c|c|c|c|}
\hline & \multicolumn{2}{|c|}{ Component-based } & \multicolumn{2}{|c|}{ Direct with pressure adjustment } & \multicolumn{2}{|c|}{$\begin{array}{l}\text { Direct without pressure } \\
\text { adjustment }\end{array}$} \\
\hline & Damage & Life (years) & Damage & Life (years) & Damage & Life (years) \\
\hline Heel & 1.74 & 11.49 & 2.07 & 9.64 & 2.04 & 9.79 \\
\hline Toe & 1.17 & 17.04 & 1.09 & 18.43 & 1.07 & 18.77 \\
\hline \multirow[t]{3}{*}{ Lug } & 0.75 & 26.84 & 0.12 & 170.58 & 0.11 & 174.60 \\
\hline & \multicolumn{2}{|c|}{ Component-based } & \multicolumn{2}{|c|}{ Direct with pressure adjustment } & \multicolumn{2}{|c|}{$\begin{array}{l}\text { Direct without pressure } \\
\text { adjustment }\end{array}$} \\
\hline & With & Without & Component & Without & Component & With \\
\hline Heel & 0.84 & 0.85 & 1.19 & 1.02 & 1.17 & 0.98 \\
\hline Toe & 1.08 & 1.10 & 0.92 & 1.02 & 0.91 & 0.98 \\
\hline Lug & 6.35 & 6.50 & 0.16 & 1.02 & 0.15 & 0.98 \\
\hline
\end{tabular}




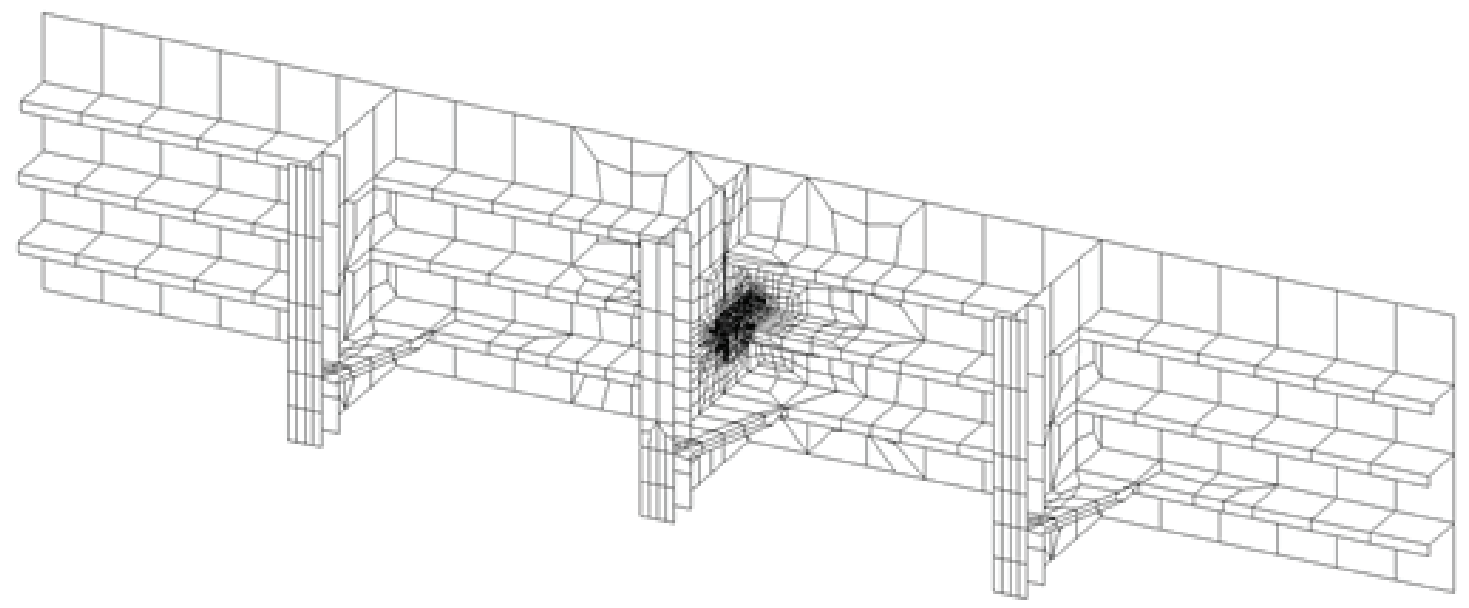

Figure 13.

Local model of stiffener through web-frame connection.
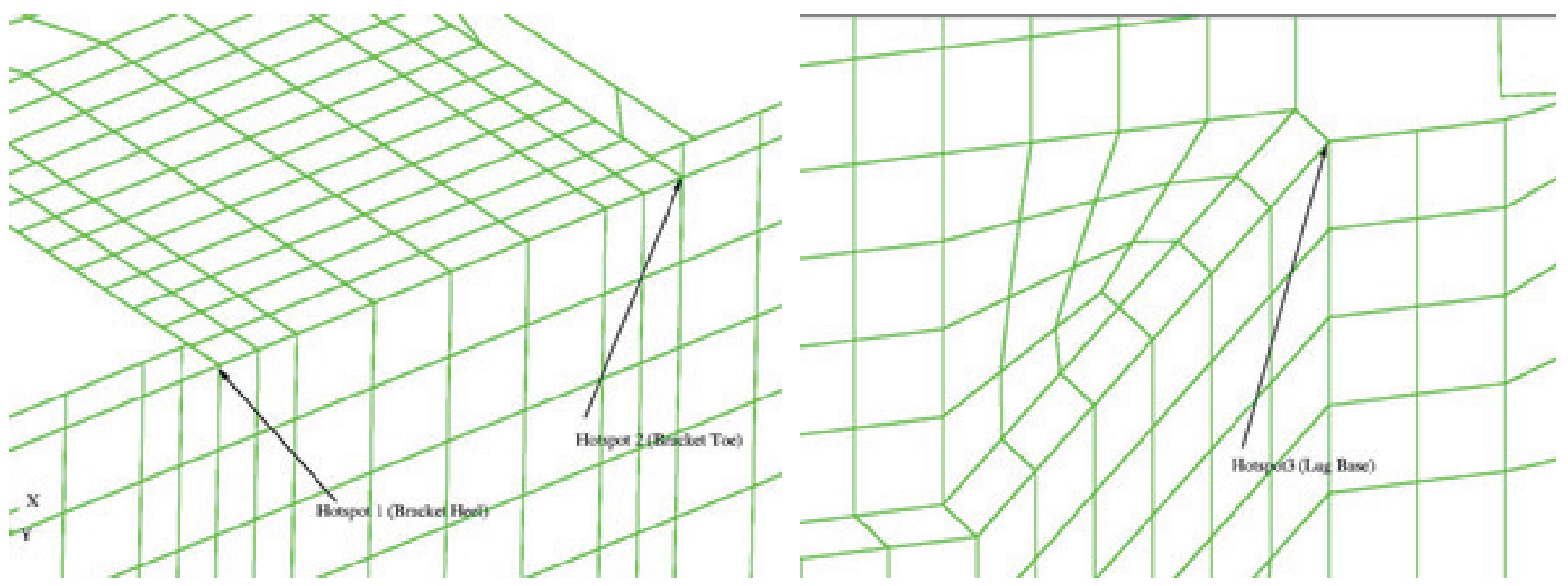

Figure 14.

Hot-spots analysed for section longitudinal 19.

\section{BOTTOM ERECTION BUTT WELD}

The hot-spots in the local model of the bottom erection butt-weld show a general trend. A slight increase in fatigue life from the component-based approach in the region of $5-10 \%$ is calculated.
The difference is most likely due to a better description of the pressure distribution in the direct application method than in the component-based approach, as it is the calculated pressure and not a linearised distribution which is applied to the model. 
Table 6.

Comparison between component based and direct application - bottom.

Bottom erection butt-weld

\begin{tabular}{|c|c|c|c|c|c|c|}
\hline & \multicolumn{2}{|c|}{ Component-based } & \multicolumn{2}{|c|}{ Direct with pressure adjustment } & \multicolumn{2}{|c|}{$\begin{array}{l}\text { Direct without pressure } \\
\text { adjustment }\end{array}$} \\
\hline & Damage & Life (years) & Damage & Life (years) & Damage & Life (years) \\
\hline Base fwd & 0.76 & 26.32 & 0.82 & 24.53 & 0.81 & 24.75 \\
\hline Mid & 1.11 & 18.02 & 1.23 & 16.21 & 1.22 & 16.34 \\
\hline Base aft & 0.85 & 23.53 & 0.92 & 21.63 & 0.92 & 21.82 \\
\hline \multirow[t]{3}{*}{ Top } & 10.07 & 1.99 & 10.67 & 1.87 & 10.57 & 1.89 \\
\hline & \multicolumn{2}{|c|}{ Component-based } & \multicolumn{2}{|c|}{ Direct with pressure adjustment } & \multicolumn{2}{|c|}{$\begin{array}{l}\text { Direct without pressure } \\
\text { adjustment }\end{array}$} \\
\hline & With & Without & Component & Without & Component & With \\
\hline Base fwd & 0.93 & 0.94 & 1.07 & 1.01 & 1.06 & 0.99 \\
\hline Mid & 0.90 & 0.91 & 1.11 & 1.01 & 1.10 & 0.99 \\
\hline Base aft & 0.92 & 0.93 & 1.09 & 1.01 & 1.08 & 0.99 \\
\hline Top & 0.94 & 0.95 & 1.06 & 1.01 & 1.05 & 0.99 \\
\hline
\end{tabular}

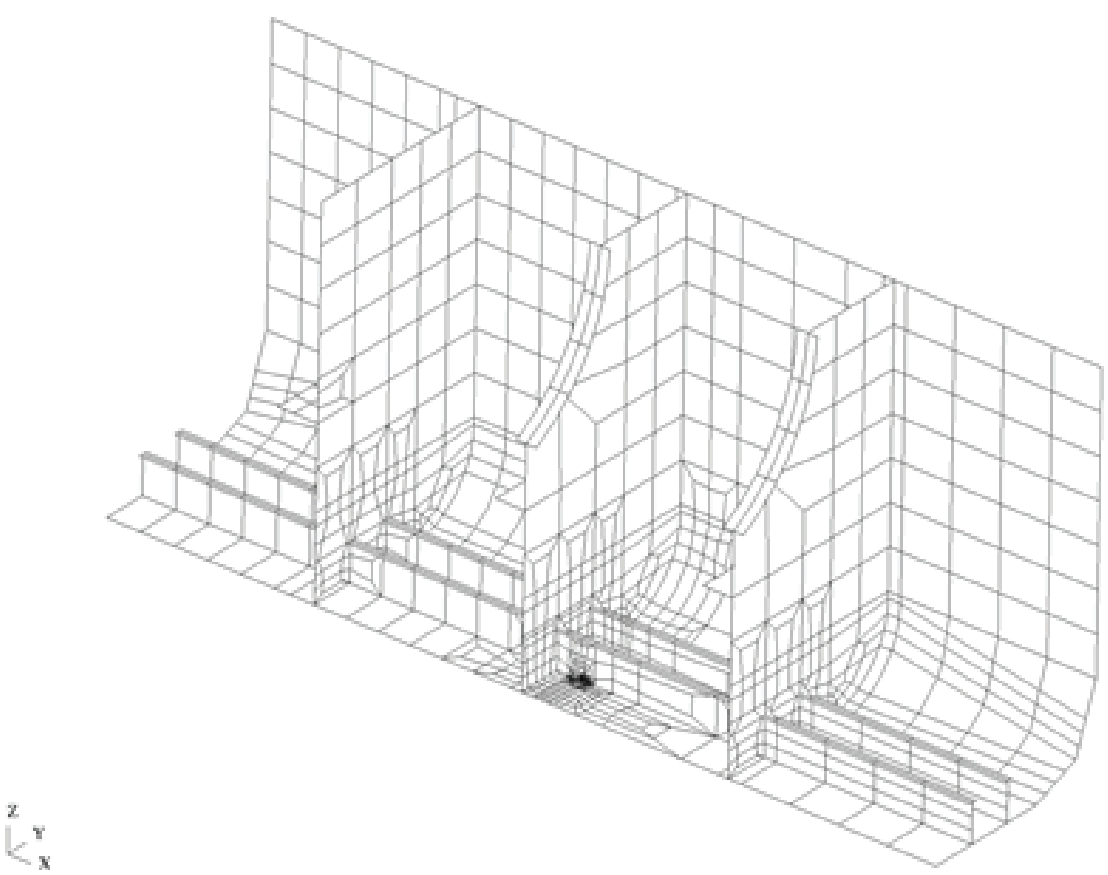

Figure 15.

Local model of bottom erection butt weld. 


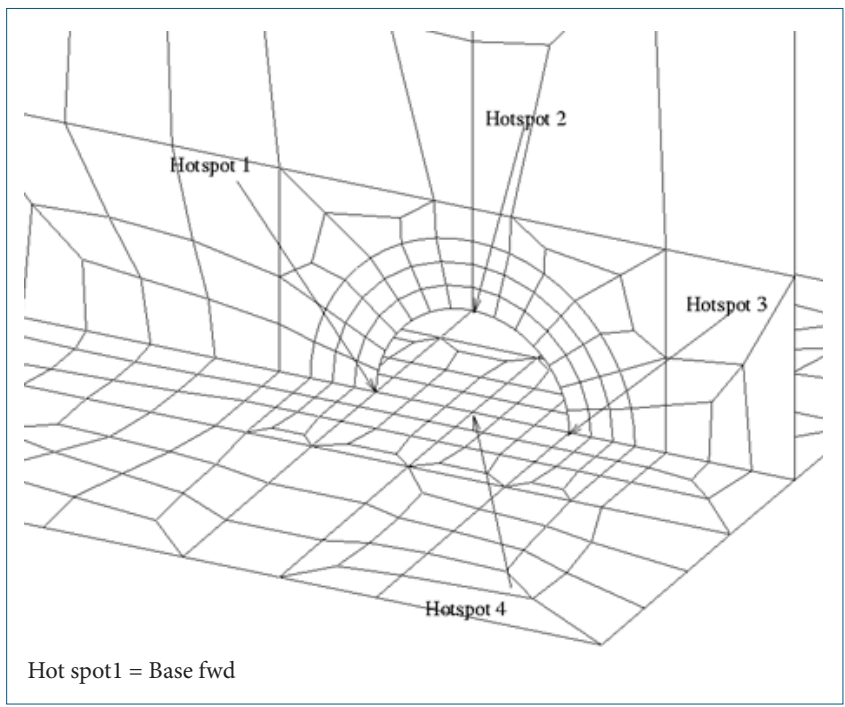

Figure 16.

Hot-spots analysed for the bottom erection butt weld.

\section{CONCLUSION AND DISCUSSION}

In general, it is found that the procedure is more robust towards input and user interpretation errors than other procedures such as component-based stochastic fatigue. The procedure offers a substantial reduction in time when considering a full stochastic calculation of fatigue life in the midship area. Typically, the fatigue calculation on a NAUTICUS midship model can be performed within 3-4 weeks after the finite element model is completed. The procedure is also very fast when considering several hotspots within one finite element model, as STOFAT module extracts the stress transfer functions automatically for each selected hot-spot.

The typical trend is that the details heavily influenced by the external pressure (side longitudinal) give less comparable results than e.g. a detail in the main deck mainly influenced by global loads. Using a typical Nauticus hull midship model, the procedure is a resource that is demanding in terms of computing capacity. The load interface files will become large, especially if internal tank pressure is necessary. Furthermore, the result file will become very large if the results for the whole midship model are required.

The following pros and cons have been developed and could be listed as:

\section{Pros}

- Large reduction in time spent on a full stochastic analysis fatigue analysis of the midship area.

- Phase relations between the various loads will always be correct; eliminates user interpretations.

- Contribution from not modelled structure taken into account as section forces at the midship model ends.

\section{Cons}

- Resource demanding when using a typical cargo hold model according to Nauticus hull mesh standard.

- Necessary to have good interaction between hydrodynamic analyst and structural analyst.

- Engineers/researchers would most probably be able to develop similar supplementary tool as described in the present study.

- Not useful for screening of structures as load specific SCF's cannot be applied.

- Only one software for extracting stresses and calculation fatigue lives; user does not need to manually extract stresses for unit load cases.

-The automatic generating of stress transfer functions enables the user to calculate the fatigue capacity for a large number of hot-spots rapidly.

-A simpler concept to use; can use existing cargo hold finite element model.
-External pressure distribution in the waterline area not verified.

-STOFAT module may be conservative for details that do not have consistent principal stress paths. 


\section{References}

Bardetsky, A. \& Lee, A., 2014. Analytical Prediction of Progressive Structural Failure of a Damaged Ship for Rapid Response Damage Assessment. Volume 4A: Structures, Safety and Reliability. Available at:

http://dx.doi.org/10.1115/omae2014-23466.

Det Norske Veritas (DNVGL) Sesam User Manual-WADAM. (2009). Wave Loads on Vessels, DNVGL Software Report.

Det Norske Veritas (DNVGL) Classification Note 30.7. Fatigue Assessment of Ship Structures, 2019.

Det Norske Veritas (DNVGL) Nauticus Hull, Nauticus Hull User Manual: "Fatigue", Fatigue Assessment, Simplified Method, 2009.

Det Norske Veritas (DNVGL) Rules for Classification of Ships, Pt. 3 Ch. 1, Hull structural design ships with length above 100 meters, 2019.

Fricke, W., 2014. Recent developments and future challenges in fatigue strength assessment of welded joints. Proceedings of the Institution of Mechanical Engineers, Part C: Journal of Mechanical Engineering Science, 229(7), pp.1224-1239. Available at:

http://dx.doi.org/10.1177/0954406214550015.

Gaidai, O. et al., 2019. Efficient fatigue assessment of ship structural details. Ships and Offshore Structures, pp.1-8. Available at: http://dx.doi.org/10.1080/17445302.2019.1661623.

González, A., 2016. Fatigue life assessment methods: the case of ship unloaders. 1st International Conference on Natural Hazards \& Infrastructure (ICONHIC 2016): Protection, Design and Rehabilitation, Chania, Greece, 28-30 June 2016.

Kim, M.H. et al., 2009. A comparative study for the fatigue assessment of a ship structure by use of hot spot stress and structural stress approaches. Ocean Engineering, 36(14), pp.1067-1072. Available at: http://dx.doi.org/10.1016/j.oceaneng.2009.07.001.

Kozak, J. \& Górski, Z., 2011. Fatigue strength determination of ship structural joints. Polish Maritime Research, 18(2). Available at:

http://dx.doi.org/10.2478/v10012-011-0009-8.

Li, Z. et al., 2014. A comparative study of fatigue assessments of container ship structures using various direct calculation approaches. Ocean Engineering, 82, pp.65-74. Available at:

http://dx.doi.org/10.1016/j.oceaneng.2014.02.022.
Magoga, T., 2019. Fatigue damage sensitivity analysis of a naval high speed light craft via spectral fatigue analysis. Ships and Offshore Structures, 15(3), pp.236-248. Available at:

http://dx.doi.org/10.1080/17445302.2019.1612543.

Niemi, E., Fricke, W. \& Maddox, S.J., 2017. Structural Hot-Spot Stress Determination Using Finite Element Analysis. Structural Hot-Spot Stress Approach to Fatigue Analysis of Welded Components, pp.17-31. Available at: http://dx.doi.org/10.1007/978-981-10-5568-3_4.

Ozguc, O., 2016. Fatigue Assessment of Longitudinal Stiffener End Connections for Ageing Tankers, Journal of Offshore Structures and Technology, 3(1), pp. 1-12.

Ozguc, O., 2017. Simplified fatigue analysis of structural details of an ageing LPG carrier. Journal of Marine Engineering \& Technology, 17(1), pp.33-42. Available at: http://dx.doi.org/10.1080/20464177.2017.1282075.

Parihar, Y., Dan, S., Doshi, K., \& Ganesan Thirunaavukarasu, S., 2017. Application of Direct Hydrodynamic Loads in Spectral Fatigue Analysis. Volume 3B: Structures, Safety and Reliability. doi:10.1115/omae2017-61907

Parunov, J., Ćorak, M. \& Gilja, I., 2013. Calculated and prescribed stress concentration factors of ship side longitudinal connections. Engineering Structures, 52, pp.629641. Available at:

http://dx.doi.org/10.1016/j.engstruct.2013.03.027.

Petinov, S. \& Guchinsky, R., 2018. Criteria for Fatigue Failure of Materials: Application in Fatigue Assessment of Structures. Advanced Engineering Forum, 26, pp.1-8. Available at:

http://dx.doi.org/10.4028/www.scientific.net/aef.26.1.

Wang, L. \& Shao, W., 2019. Research on the Calculation of Accumulated Fatigue Damage for Ship Structures. 2019 4th International Conference on Mechanical, Control and Computer Engineering (ICMCCE). Available at: http://dx.doi.org/10.1109/icmcce48743.2019.00025.

Xiang-chun, L., Guo-qing, F. \& Hui-long, R., 2006. Study on the application of spectral fatigue analysis. Journal of Marine Science and Application, 5(2), pp.42-46. Available at: http://dx.doi.org/10.1007/s11804-006-0034-7. 